\title{
Short-term analysis of uniport video-assisted thoracoscopic surgery via the subxiphoid approach without chest tube drainage for anterior mediastinal tumors: a comparative retrospective study
}

\author{
Min Cao", Qing Wang", Hang Yin, Yujie Fu, Xiaojing Zhao \\ Department of Thoracic Surgery, Renji Hospital, Shanghai Jiao Tong University School of Medicine, Shanghai, China \\ Contributions: (I) Conception and design: M Cao, Q Wang; (II) Administrative support: Y Fu, X Zhao; (III) Provision of study materials or patients: \\ Y Fu, X Zhao; (IV) Collection and assembly of data: M Cao, Q Wang; (V) Data analysis and interpretation: Q Wang; (VI) Manuscript writing: All \\ authors; (VII) Final approval of manuscript: All authors. \\ "These authors contributed equally to this work. \\ Correspondence to: Xiaojing Zhao, MD; Yujie Fu, MD, PhD. Department of Thoracic Surgery, Renji Hospital, Shanghai Jiao Tong University School \\ of Medicine, 160 Pujian Road, Shanghai 200127, China. Email: zhaoxiaojing@renji.com; richardjiejie@hotmail.com.
}

Background: Uniport video-assisted thoracoscopic surgery (VATS) via the subxiphoid approach has
emerged as a safe and effective treatment for anterior mediastinal tumors. However, there is limited evidence
of the necessity of chest tubes and the comparative efficacy with other approaches.
Methods: A total of 141 patients with anterior mediastinal tumors receiving VATS were enrolled in this
retrospective study. The patients were divided into the lateral approach (LA) group, the uniport subxiphoid
approach (USA) group, and the three-port subxiphoid approach (TSA) group. Short-term analysis including
operation time, chest tube rates, drainage duration, visual analogue scale (VAS) score, and hospital stay were
compared. Postoperative CT scans were analyzed to evaluate the amount of pleural effusion.
Results: There was no significant difference in demographic and baseline characteristics among the three
groups (all P>0.05). The operation time, blood loss, and hospital stay of the subxiphoid approach group
were significantly lower than the LA group ( $<<0.001)$. The postoperative CT scans demonstrated that the
USA group had a similar amount of pleural effusion as the other groups $(\mathrm{P}=0.1605)$. The postoperative VAS
score of the USA group was significantly lower than the other groups $(\mathrm{P}<0.001)$. There was no significant
difference in complications, in-hospital death, and conversion to thoracotomy among the three groups (all
P>0.05).

Conclusions: VATS via the subxiphoid approach is less invasive, equally safe, and same effective for anterior mediastinal tumors than the LA. The chest tube could be omitted for the USA.

Keywords: Subxiphoid approach; video-assisted thoracoscopic surgery (VATS); uniport; three-port; anterior mediastinal tumors; short-term efficacy

Submitted Sep 24, 2021. Accepted for publication Nov 19, 2021.

doi: $10.21037 /$ atm-21-5790

View this article at: https://dx.doi.org/10.21037/atm-21-5790

\section{Introduction}

Anterior mediastinal tumor is a common disease in thoracic surgery, and surgical resection has been widely applied as the primary treatment strategy (1). Traditional median sternal incision can well expose the anterior mediastinum tissue, which has long been the "gold standard" operation to treat anterior mediastinal diseases. However, this surgical method causes massive trauma to the patient, leading to prolonged postoperative recovery and a significant impact on respiratory and circulatory function (2). In recent years, traditional median sternal incision has been gradually replaced by video-assisted thoracoscopic surgery (VATS). 
Compared with traditional sternotomy, the VATS not only shortens the hospital stay and thoracic drainage time with less invasiveness but also achieves the same treatment efficacy with non-inferior overall survival and recurrence rate $(3,4)$. Despite the relatively limited exposure, VATS through the lateral approach (LA), has achieved satisfying efficacy for the treatment of anterior mediastinal tumors. Especially for patients with Masaoka stage I-II thymoma, the 5-year overall survival has achieved comparable results with thoracotomy (5). However, VATS through the LA still has certain limitations.

Through the LA (intercostal), the thoracoscope the contralateral phrenic nerve and the upper pole of the thymus, increasing the risk of intraoperative damage to phrenic nerve-related blood vessels. On the other hand, the intercostal nerve injury caused by the intercostal incision is inevitable, resulting in chronic postoperative intercostal neuralgia and skin paresthesia in the nerve distribution area (6). Suda $e t$ al. proposed a surgical approach via the subxiphoid approach, which effectively avoided intercostal nerve injury (7). Establishing artificial pneumothorax through $\mathrm{CO}_{2}$ increases the anterior mediastinal space and provides a safer surgical operation environment. Simultaneously, the visual field of thoracoscopy placed in the center direction can reveal the bilateral phrenic nerve and the upper pole of the thymus, hence obtaining visual field exposure similar to open thoracotomy. According to the number of ports, the subxiphoid approach can be divided into three-port and uniport. Nevertheless, there is limited evidence of the efficacy and safety of subxiphoid approach VATS for anterior mediastinal tumors, especially a comparison of three-port and uniport incisions. In this study, we retrospectively analyzed 141 cases with anterior mediastinal tumors who received VATS resection and aimed to explore the advantages and disadvantages of different surgical approaches. We present the following article in accordance with the STROBE reporting checklist (available at https://dx.doi.org/10.21037/atm-21-5790).

\section{Methods}

\section{Study cobort and clinical data}

We retrospectively reviewed all patients undergoing VATS resection for anterior mediastinal tumors from Jan 2016 to Jan 2021 and screened patients meeting the following inclusion criteria: (I) patients were adults ( $\geq 18$ years old); (II) patients were diagnosed with an anterior mediastinal tumor and undergoing VATS resection; (III) patients had complete clinical data and CT scan files. The exclusion criteria were as follows: (I) patients who received median sternotomy; (II) patients who had malignant tumors with apparent invasion to neighboring organs.

\section{Ethical statement}

All procedures performed in this study involving human participants were in accordance with the Declaration of Helsinki (as revised in 2013). The study was approved by the ethics committee of Renji Hospital, Shanghai Jiaotong University School of Medicine (No. 2017-082). Individual consent for this retrospective analysis was waived.

\section{Surgical technique}

\section{LA}

As previously described, we used the classic three-port intercostal approach (7). The patients were placed in a supine position. Three skin incisions were made on the anterior axillary line in the third intercostal space, the anterior axillary line, and the midaxillary line in the fifth intercostal space. In most cases, the anterior mediastinal tumor was approached from the right side of the chest. When the tumor was predominantly on the left side, the tumor was approached from the left side of the chest. For patients with myasthenia gravis (MG) or positive antiacetylcholine receptor antibodies, we adopted the lateral intercostal approach from both sides to remove all adipose tissue anterior to both phrenic nerves (Figure 1A).

\section{Three-port subxiphoid approach (TSA)}

The patient was placed in the lithotomy position. After disinfection, a $3-4 \mathrm{~cm}$ transverse or vertical incision was made under the xiphoid. The sternum was bluntly separated from the anterior mediastinum, and a thoracoscope was inserted. A $0.5-1 \mathrm{~cm}$ surgical incision was made at the junction of the bilateral midclavicular line and the costal arch, and a trocar was placed close to the costal arch toward the xiphoid. Artificial pneumothorax was made with $\mathrm{CO}_{2}$ pressure of $8-10 \mathrm{mmHg}$. The bilateral pleura was opened with an ultrasonic knife to enter the bilateral thoracic cavity. The loose connective tissue of the anterior mediastinum along the sternum's posterior edge was thoroughly dissected until the left innominate vein's level. The bilateral phrenic nerves were fully exposed, and the mediastinal pleura along the phrenic nerve was ultimately opened. On the right side, 
A

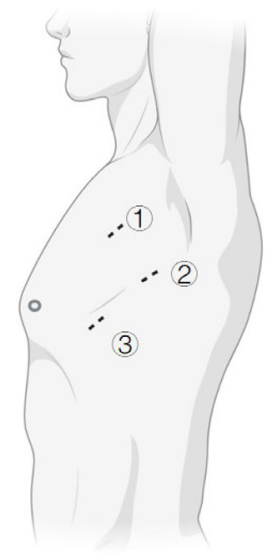

LA
B

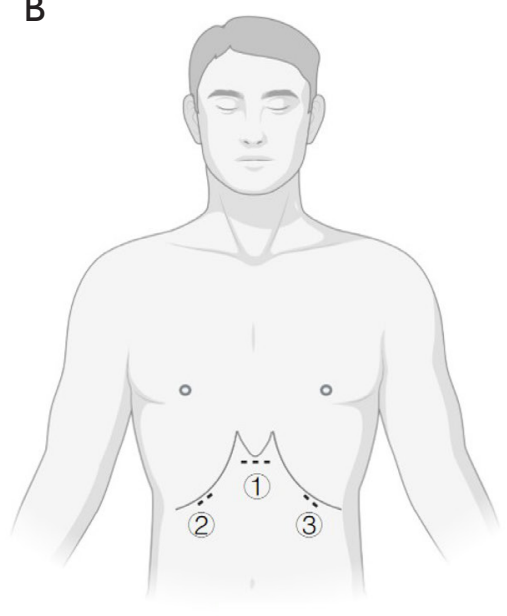

C

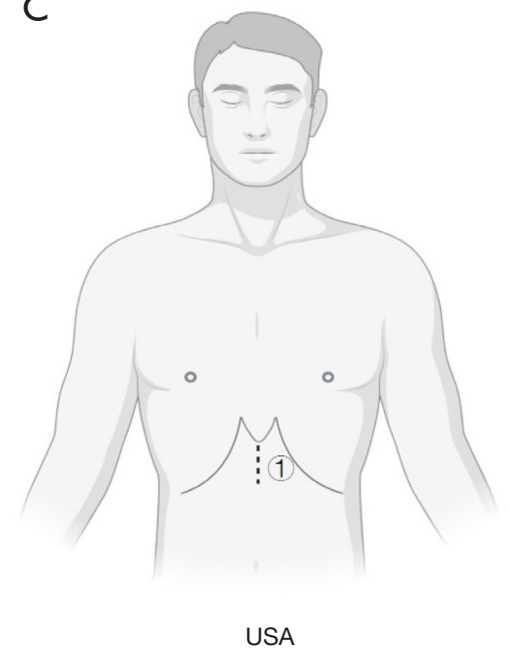

Figure 1 The skin incisions of the three approaches. (A) The LA: (1) $1 \mathrm{~cm}$ incision at the anterior axillary line in the third intercostal space as the operating port; (2) $1 \mathrm{~cm}$ incision at the midaxillary line in the fifth intercostal space as the observational port; (3) $0.5 \mathrm{~cm}$ incision at the anterior axillary line in the fifth intercostal space as the operating port; (B) the TSA: (1) 3 to 4 cm transverse or vertical incision under the xiphoid process as the observational port; (2) (3) a $0.5-1 \mathrm{~cm}$ incision at the intersection of the bilateral midclavicular line and the costal arch as the operating hole; (C) the USA: (1) 3 to $4 \mathrm{~cm}$ transverse or vertical incision under the xiphoid process. LA, lateral approach; TSA, threeport subxiphoid approach; USA, uniport subxiphoid approach.

the left innominate vein was exposed along the superior vena cava. The left innominate vein and bilateral upper poles of the thymus were carefully dissociated from right to left. The thymic veins were cut off with an ultrasonic knife. The specimen was taken out from the major incision under the xiphoid (Figure 1B).

\section{Uniport subxiphoid approach (USA)}

Only 1 transverse or vertical skin incision of 3-4 cm was made beneath the xiphoid, and the subsequent procedures were the same as the TSA (Figure 1C).

\section{Chest tube placement}

After the surgery, the chest tube was placed in the incision and connected to the negative pressure drainage ball. The lung was re-expanded by the anesthesiologist until no air leaked before the incision was closed. For patients with minor wounds and bleeding, the chest tube was removed immediately after the drain site was sutured.

\section{Postoperative management}

All patients were extubated after the surgery and transferred to the ward. Bedside chest radiography was routinely conducted to monitor postoperative bleeding, pneumothorax, and pleural effusion on the day of surgery. Blood examination was performed on the first and third postoperative days (PODs). Postoperative analgesia, including intravenous tramadol, oral nonsteroidal analgesics, and acetaminophen, was administered. The visual analogue scale (VAS) was applied to evaluate postoperative pain on the first 3 PODs. For patients with MG, the same medications used preoperatively were continued after the operation under the guidance of the neurologist. A CT scan was also conducted 2-3 days after the surgery. The chest tube would be removed if the drainage was less than $200 \mathrm{~mL} /$ day and the lung was wholly recruited.

\section{Data collection}

All data were collected from the hospital's electronic record system. Demographic characteristics and clinical data were collected, including age, gender, body mass index (BMI), tumor type, tumor size, MG, and comorbidities. Shortterm outcomes of all patients, including operation time, blood loss, conversion to thoracotomy, in-hospital death, hospital stays, chest tube drainage, postoperative VAS score, and complications, were also investigated. Two independent radiologists were invited to download and analyze the 
postoperative CT scan DICOM files of all patients to assess the amount of pleural effusion.

\section{Statistical analysis}

SPSS ver. 21.0 (IBM SPSS Statistics, Chicago, IL, USA) was used to perform all statistical analyses. Continuous variables are presented as mean \pm standard deviation (SD). Categorical variables are presented as numbers (percentages). Analysis of variance (ANOVA) was conducted to compare continuous variables meeting the normal distribution among the three groups, while the least significant difference (LSD) $t$-test was used for the posthoc test. The Chi-square test was performed to compare categorical variables of different groups, while partitions of the Chi-square test were adopted as the method for the post-hoc test. A P value less than 0.05 was considered statistically significant.

\section{Results}

\section{Demographic and baseline characteristics}

A total of 141 patients were enrolled in this study, including 51 patients who received VATS through the LA (LA group), 57 patients who received VATS through the USA (USA group), and 33 patients who received VATS through the TSA (TSA group). As shown in Table 1, we compared the demographic and baseline characteristics of the three groups. There was no significant difference among the three groups in demographic data, including age, gender, $\mathrm{BMI}$, and comorbidities (all $\mathrm{P}>0.05$ ). We also found that the three groups demonstrated similar tumor type proportions $(\mathrm{P}=0.640)$. Most patients $(64.5 \%)$ were diagnosed with thymoma in the three groups. There was also no difference in WHO type and Masaoka stage among the three groups $(\mathrm{P}>0.05)$. Fourteen patients (9.9\%) were complicated by MG.

\section{Short-term outcomes}

The short-term outcomes of the three groups were compared, as shown in Table 2. No in-hospital death occurred. Only 1 patient in the USA group was converted to open thoracotomy due to major bleeding, while there was no difference in the incidence of conversion to thoracotomy among three groups $(\mathrm{P}=0.476)$. The subxiphoid approach demonstrated a significant advantage in less blood loss, operation time, and hospital stay, whether in the USA or
TSA group (all $\mathrm{P}<0.001$ ). However, there was no statistical difference in blood loss, operation time, and hospital stay between the USA and TSA groups (both $\mathrm{P}>0.05$ ). As for postoperative pain, we found that the USA group presented a lower VAS score than the other two groups at POD1 and POD2, but not POD3. The TSA and LA groups showed no significant differences in postoperative complications, including phrenic nerve paralysis, effusion/pneumothorax requiring thoracocentesis, and dyspnea (all $\mathrm{P}>0.05$ ). In terms of laboratory results, white blood cell count (WBC), C-reactive protein (CRP), and hemoglobin ( $\mathrm{Hgb}$ ) showed no significant differences among the three groups at POD1 and POD3 (all $\mathrm{P}>0.05$ ).

\section{Chest tube and drainage}

We also compared the chest tube rates of the three groups and the drainage, as shown in Table 2. During the operation, the surgeon would decide whether to place the chest tube or not according to their experience. We summarized the chest tube rates of the three groups and found that the USA group had the lowest chest tube rate of $21.1 \%(\mathrm{P}<0.001)$. The postoperative drainage from the chest tube was comparable among the three groups, as well as the drainage duration (both $\mathrm{P}>0.05$ ). We used $\mathrm{CT}$ to calculate the amount of pleural effusion in the three groups and found no significant difference (Figure 2) $(\mathrm{P}=0.1605)$.

\section{Discussion}

Recent years have witnessed the surging development of minimally invasive approaches in thoracic surgery. Despite the gold standard of median sternotomy in thymectomy for anterior mediastinal tumors, VATS has emerged as the most frequently used procedure due to its minimal invasiveness $(8,9)$. This study retrospectively compared three VATS approaches for anterior mediastinal tumors, including their short-term outcomes, surgery-related indicators, and postoperative pleural effusion amount. Three significant findings were made in this study: (I) the subxiphoid approach had a shorter operation time, less blood loss, and shorter hospital stay than the LA; (II) patients who received uniport incisions had lower VAS scores than patients with three-port incisions; (III) uniport patients without chest tubes did not have a higher amount of pleural effusion and thoracocentesis.

Anterior mediastinal tumors are the most common mediastinal tumors (10). Surgical resection has always 
Table 1 Demographic and clinical characteristics of the three groups

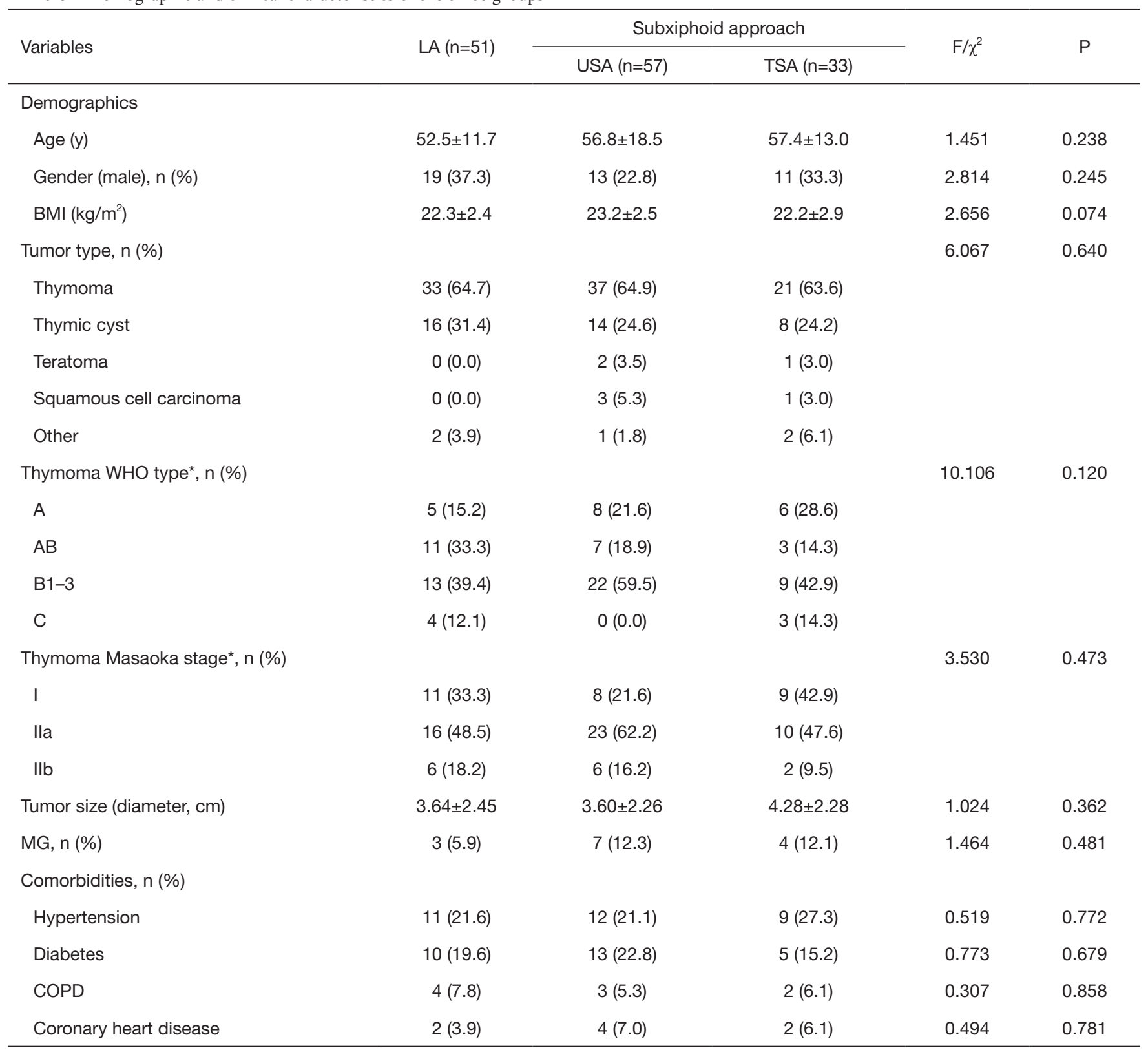

Continuous variables are presented as mean $\pm \mathrm{SD}$. Categorical variables are presented as $\mathrm{n}$ (proportions). *, percentage of cases with thymoma. LA, lateral approach; USA, uniport subxiphoid approach; TSA, three-port subxiphoid approach; BMI, body mass index; MG, myasthenia gravis; COPD, chronic obstructive pulmonary disease; SD, standard deviation.

been the preferred treatment option (11). The surgical route of the median sternum incision is still the primary surgical method for treating anterior mediastinal tumors. This surgical method can clearly show the structure of the anterior mediastinum, which helps clarify the relationship between the tumor and the mediastinal vessels. The surgery is still the first choice for tumors involving the mediastinum's essential structures (12), though this surgical approach is very traumatic and significantly impacts the patient's cardiopulmonary function. As more and more benign and early malignant mediastinal diseases are discovered and diagnosed, the shortcomings of median sternotomy have gradually increased. At the same time, minimally invasive VATS technology is 
Table 2 Perioperative data and in-hospital outcomes

\begin{tabular}{|c|c|c|c|c|c|}
\hline Variables & $L A(n=51)$ & \multicolumn{2}{|c|}{ Subxiphoid approach } & $F / \chi^{2}$ & $\mathrm{P}$ \\
\hline Operation time (min) & $123.1 \pm 38.0$ & $90.1 \pm 17.8^{*}$ & $100.4 \pm 23.0^{\star}$ & 18.584 & $<0.001$ \\
\hline Conversion to thoracotomy, $\mathrm{n}(\%)$ & $0(0.0)$ & $1(1.8)$ & $0(0.0)$ & 1.484 & 0.476 \\
\hline Blood loss (mL) & $53.7 \pm 15.5$ & $44.4 \pm 9.4^{*}$ & $43.8 \pm 10.7^{*}$ & 9.879 & $<0.001$ \\
\hline Hospital stay (d) & $4.6 \pm 1.4$ & $3.5 \pm 0.5^{\star}$ & $3.9 \pm 0.8^{*}$ & 17.474 & $<0.001$ \\
\hline Chest tube, n (\%) & $51(100.0)$ & $12(21.1)^{*}$ & $30(90.9)^{\#}$ & 86.661 & $<0.001$ \\
\hline \multicolumn{6}{|l|}{ Chest tube drainage $(\mathrm{mL})$} \\
\hline POD1 & $221.4 \pm 46.0$ & $211.7 \pm 34.9$ & $227.0 \pm 55.6$ & 1.370 & 0.256 \\
\hline \multicolumn{6}{|l|}{ Postoperative VAS score } \\
\hline POD1 & $4.9 \pm 1.5$ & $3.7 \pm 1.5^{\star}$ & $5.3 \pm 1.3^{\#}$ & 15.958 & $<0.001$ \\
\hline POD2 & $3.8 \pm 1.7$ & $2.6 \pm 1.7^{\star}$ & $4.3 \pm 1.5^{\#}$ & 13.639 & $<0.001$ \\
\hline POD3 & $2.7 \pm 1.7$ & $2.0 \pm 1.3$ & $2.6 \pm 1.9$ & 2.563 & 0.081 \\
\hline \multicolumn{6}{|l|}{ Complications, n (\%) } \\
\hline Phrenic nerve paralysis & $1(2.0)$ & $0(0.0)$ & $0(0.0)$ & 1.777 & 0.411 \\
\hline $\begin{array}{l}\text { Effusion/pneumothorax requiring } \\
\text { thoracocentesis }\end{array}$ & $0(0.0)$ & $2(3.5)$ & $1(3.0)$ & 1.760 & 0.415 \\
\hline POD1 & $56.7 \pm 19.2$ & $47.0 \pm 16.4^{*}$ & $58.2 \pm 19.8^{\#}$ & 5.349 & 0.006 \\
\hline POD3 & $12.1 \pm 8.0$ & $12.3 \pm 4.4$ & $12.6 \pm 8.9$ & 0.068 & 0.934 \\
\hline \multicolumn{6}{|l|}{$\mathrm{Hgb}(\mathrm{g} / \mathrm{L})$} \\
\hline POD1 & $126.7 \pm 12.1$ & $131.0 \pm 6.7$ & $129.6 \pm 11.1$ & 2.580 & 0.079 \\
\hline POD3 & $121.5 \pm 12.8$ & $126.5 \pm 7.3$ & $124.3 \pm 11.5$ & 3.020 & 0.052 \\
\hline
\end{tabular}

Continuous variables are presented as mean \pm SD. Categorical variables are presented as $\mathrm{n}$ (proportions). Subxiphoid approach vs. LA, ${ }^{*}$, $\mathrm{P}<0.05$; three-port vs. uniport, ", $\mathrm{P}<0.05$. LA, lateral approach; USA, uniport subxiphoid approach; TSA, three-port subxiphoid approach; VAS, visual analogue scale; POD, postoperative day; WBC, white blood cell count; CRP, C-reactive protein; Hgb, hemoglobin; SD, standard deviation.

developing fast. VATS via the LA has been widely used in the treatment of anterior mediastinal tumors. Compared with median sternotomy, VATS via the LA has minor trauma characteristics and results in quick recovery after the operation (9), but this surgical method still has its shortcomings. For the unilateral approach, whether it is a single or three-port approach, it is difficult to expose the contralateral phrenic nerve, the upper pole of the thymus, 
and the fatty tissue at the heart-phrenic angle, which increases intraoperative injury and residual risk. Especially for cases with MG, the residual thymus and surrounding adipose tissue are not conducive to alleviating myasthenia symptoms and even induces myasthenic crisis (13). Some studies have proposed that the bilateral thoracoscopic approach for treating anterior mediastinal tumors with $M G$ can completely remove the thymus and surrounding adipose tissue and effectively relieve the symptoms of myasthenia (14-16). However, bilateral thoracoscopic surgery requires changing the patient's position during the operation, which significantly prolongs the operation time and increases the occurrence of postoperative complications. At the same time, due to possible intercostal nerve damage caused by the LA, the incidence of intercostal nerve paralysis and neuralgia increased significantly (17).

Suda et al. proposed a new VATS approach to remove the thymus through the subxiphoid approach, effectively avoiding intercostal nerve injury and reducing postoperative intercostal nerve pain (7). We successfully applied this surgical approach to treat anterior mediastinal tumors without surrounding tissue invasion or limited local invasion. There were no cases of perioperative death. Only 1 patient was converted to open-chest surgery due to massive bleeding caused by incidental injury of the left innominate vein. According to the number of ports, the subxiphoid approach could be divided into uniport and three-port types. For the uniport approach, a 3 to $5 \mathrm{~cm}$ transverse or vertical incision is made just over the xiphoid process's prominence depending on the width of the angle between the subcostal margins (14) (Figure 1C). For the three-port approach, a thoracoscope for observation of the operation area is inserted through an incision of about $3-4 \mathrm{~cm}$ under the xiphoid, with two $0.5-1 \mathrm{~cm}$ incisions at the intersection of the bilateral midclavicular line and the costal arch as the operating hole to insert the trocar (Figure 1B). Artificial pneumothorax pressure of $8-10 \mathrm{mmHg}$ expands the anterior mediastinum space to better display the surgical field of vision.

Through 90 cases of VATS via the subxiphoid approach within 5 years, we found that this procedure can expose the bilateral phrenic nerves, avoiding phrenic nerve injury caused by inadequate visual field exposure during the operation. Simultaneously, the surgical approach is satisfactory for the exposure of the bilateral thymus and the upper pole of the thymus. The complete removal of the bilateral thymus and surrounding adipose tissue is significant for anterior mediastinal disease with myasthenia symptoms. Eleven surgical cases with muscle weakness symptoms in this study were effectively relieved after the operation. We also found that the subxiphoid approach groups had significantly lower operation times, blood loss, and hospital stays than the LA group (all $\mathrm{P}<0.001$ ), indicating that the subxiphoid approach was less invasive and more helpful for postoperative recovery. Mao et al. also compared the subxiphoid and intercostal approaches in anterior mediastinal tumor surgery. They found that the VAS score was lower in patients who underwent the subxiphoid approach than in the intercostal group. Postoperative drainage time, postoperative drainage volume, and hospitalization time were significantly increased in the left thoracic approach group compared with the right thoracic approach group (6). According to previous reports, the most likely complication of the LA approach is phrenic nerve paralysis, while for the subxiphoid approach, it is dyspnea (18). The incidence of postoperative complications is very low and does not affect long-term pain. This study also found a very low incidence of postoperative complications, with no statistical difference among the three groups.

Furthermore, we found that the USA group had a lower VAS score than the TSA group. The primary reason is that most patients in the USA group (45/57) did not have chest tube placement after the surgery. The chest tube is one of the significant reasons for postoperative pain (19). We found that the USA approach led to better exposure and hemostasis during our subxiphoid approach, making the omission of chest tubes possible. To ensure safety, we conducted routine bedside X-rays, laboratory tests, and CT scans. No severe postoperative bleeding or pneumothorax was found in all patients. We also used CT scan reconstructions to estimate the amount of pleural effusion, which indicated no statistical difference among the three groups. Li et al. also found no difference between patients with or without chest tubes regarding the incidence of dyspnea and delayed pleural effusion requiring thoracentesis after chest tube removal (20). Recent studies have witnessed the progress of VATS surgical technique via subxiphoid approach, including the non-intubation, "fourzone one-way" method, which further decreased the trauma and enhanced the postoperative recovery $(21,22)$.

Several limitations of this study must be noted. First, this study was a retrospective study, and selection bias could not be avoided even with no statistical difference in baseline characteristics. We've tried to apply the propensity score match to mitigate the baseline bias, but this method was only 

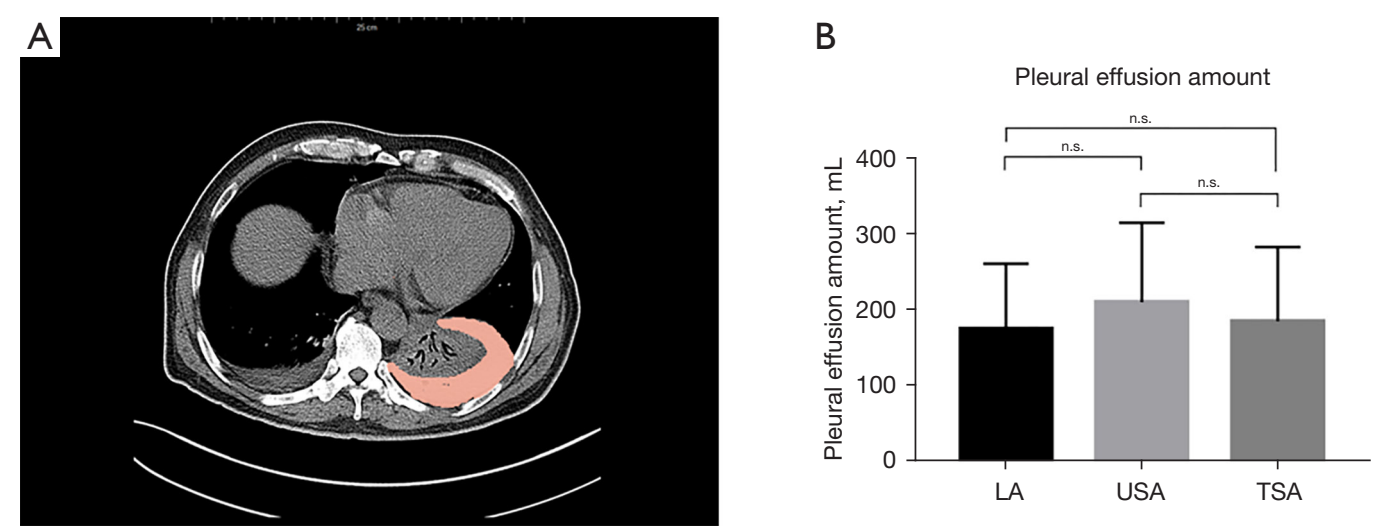

Figure 2 The postoperative CT scan results and estimated pleural effusion amounts. (A) Pleural effusion depicted by CT scan software; (B) pleural effusion amount estimation of the three groups. LA, lateral approach; USA, uniport subxiphoid approach; TSA, three-port subxiphoid approach; n.s., not significant.

suitable for two groups. What's more, the demographical data and baseline characteristics were comparable among the three groups, indicating the bias was under control, which might not influence the final results (23). Also, the sample size of this study was relatively small, and all patients were from a single center, which lowered the evidence level. A prospective, multicenter clinical trial with more patients might be required to validate the conclusions. Second, the long-term outcome of the surgery was not included because of the lack of follow-up results. Whether the approach affects the long-term survival of patients with anterior mediastinal tumors needs further investigation. Lastly, the learning curve and the surgeon's experience could impact the results, which should be taken into consideration.

\section{Conclusions}

The subxiphoid approach is less invasive and equally effective in VATS surgery for anterior mediastinal tumors. For the subxiphoid approach, the uniport approach leads to less pain and reliable hemostasis when the omission of the chest tube is feasible.

\section{Acknowledgments}

Funding: None.

\section{Footnote}

Reporting Checklist: The authors have completed the STROBE reporting checklist. Available at https:// dx.doi.org/10.21037/atm-21-5790

Data Sharing Statement: Available at https://dx.doi. org/10.21037/atm-21-5790

Conflicts of Interest: All authors have completed the ICMJE uniform disclosure form (available at https://dx.doi. org/10.21037/atm-21-5790). The authors have no conflicts of interest to declare.

Ethical Statement: The authors are accountable for all aspects of the work in ensuring that questions related to the accuracy or integrity of any part of the work are appropriately investigated and resolved. All procedures performed in this study involving human participants were in accordance with the Declaration of Helsinki (as revised in 2013). The study was approved by the ethics committee of Renji Hospital, Shanghai Jiaotong University School of Medicine (No. 2017-082). Individual consent for this retrospective analysis was waived.

Open Access Statement: This is an Open Access article distributed in accordance with the Creative Commons Attribution-NonCommercial-NoDerivs 4.0 International License (CC BY-NC-ND 4.0), which permits the noncommercial replication and distribution of the article with the strict proviso that no changes or edits are made and the original work is properly cited (including links to both the formal publication through the relevant DOI and the license). See: https://creativecommons.org/licenses/by-nc-nd/4.0/. 


\section{References}

1. Carter BW, Marom EM, Detterbeck FC. Approaching the patient with an anterior mediastinal mass: a guide for clinicians. J Thorac Oncol 2014;9:S102-9.

2. Seong YW, Kang CH, Choi JW, et al. Early clinical outcomes of robot-assisted surgery for anterior mediastinal mass: its superiority over a conventional sternotomy approach evaluated by propensity score matching. Eur J Cardiothorac Surg 2014;45:e68-73; discussion e73.

3. Agatsuma H, Yoshida K, Yoshino I, et al. Video-Assisted Thoracic Surgery Thymectomy Versus Sternotomy Thymectomy in Patients With Thymoma. Ann Thorac Surg 2017;104:1047-53.

4. Liu TJ, Lin MW, Hsieh MS, et al. Video-assisted thoracoscopic surgical thymectomy to treat early thymoma: a comparison with the conventional transsternal approach. Ann Surg Oncol 2014;21:322-8.

5. Xie A, Tjahjono R, Phan K, et al. Video-assisted thoracoscopic surgery versus open thymectomy for thymoma: a systematic review. Ann Cardiothorac Surg 2015;4:495-508.

6. Mao Y, Lan Y, Cui F, et al. Comparison of different surgical approaches for anterior mediastinal tumor. J Thorac Dis 2020;12:5430-9.

7. Suda T, Hachimaru A, Tochii D, et al. Video-assisted thoracoscopic thymectomy versus subxiphoid single-port thymectomy: initial results $†$. Eur J Cardiothorac Surg 2016;49 Suppl 1:i54-8.

8. Melfi FM, Fanucchi O, Mussi A. Minimally invasive mediastinal surgery. Ann Cardiothorac Surg 2016;5:10-7.

9. Ferreira R, Junqueira N, Rodrigues M, et al. Inframammary approach for addressing anterior mediastinal tumours: initial experience. J Thorac Dis 2020;12:2077-81.

10. Strollo DC, Rosado de Christenson ML, Jett JR. Primary mediastinal tumors. Part 1: tumors of the anterior mediastinum. Chest 1997;112:511-22.

11. Trousse D, Avaro JP. Mediastinal tumors: introduction. Rev Pneumol Clin 2010;66:3-16.

12. Bacha EA, Chapelier AR, Macchiarini P, et al. Surgery for invasive primary mediastinal tumors. Ann Thorac Surg 1998;66:234-9.

13. Comacchio GM, Marulli G, Mammana M, et al. Surgical Decision Making: Thymoma and Myasthenia Gravis. Thorac Surg Clin 2019;29:203-13.
14. Abu-Akar F, Gonzalez-Rivas D, Yang C, et al. Subxiphoid Uniportal VATS for Thymic and Combined Mediastinal and Pulmonary Resections - A Two-Year Experience. Semin Thorac Cardiovasc Surg 2019;31:614-9.

15. Kanzaki M, Kikkawa T, Obara T, et al. Successful excision of an isolated mediastinal cystic lymphangioma with bilateral thoracoscopic surgery. Ann Thorac Cardiovasc Surg 2011;17:570-2.

16. Nakagawa M, Kohno T, Mun M, et al. Bilateral videoassisted thoracoscopic surgery resection for multiple mediastinal myelolipoma: report of a case. Korean J Thorac Cardiovasc Surg 2014;47:189-92.

17. Furrer M, Rechsteiner R, Eigenmann V, et al. Thoracotomy and thoracoscopy: postoperative pulmonary function, pain and chest wall complaints. Eur J Cardiothorac Surg 1997;12:82-7.

18. Yano M, Moriyama S, Haneda H, et al. The Subxiphoid Approach Leads to Less Invasive Thoracoscopic Thymectomy Than the Lateral Approach. World J Surg 2017;41:763-70.

19. Kaplan JA, Miller ED Jr, gallagher EG Jr. Postoperative analgesia for thoracotomy patients. Anesth Analg 1975;54:773-7.

20. Li J, Qi G, Zhang X, et al. Is chest tube drainage necessary after subxiphoid thoracoscopic thymectomy? J Cardiothorac Surg 2020;15:66.

21. Mao Y, Liang H, Deng S, et al. Non-intubated videoassisted thoracic surgery for subxiphoid anterior mediastinal tumor resection. Ann Transl Med 2021;9:403.

22. Gao L, Lu J, Shen Z, et al. A novel method of subxiphoid video-assisted thoracic surgery for thymectomy. Ann Transl Med 2021;9:1339.

23. Reiffel JA. Propensity Score Matching: The 'Devil is in the Details' Where More May Be Hidden than You Know. Am J Med 2020;133:178-81.

(English Language Editor: C. Betlzar)

Cite this article as: Cao M, Wang Q, Yin H, Fu Y, Zhao X. Short-term analysis of uniport video-assisted thoracoscopic surgery via the subxiphoid approach without chest tube drainage for anterior mediastinal tumors: a comparative retrospective study. Ann Transl Med 2021;9(22):1687. doi: 10.21037/atm-215790 